\title{
THE ChemSM-Hub PROJECT IN THE LIGHT OF A NEW PARADIGM FOR CHEMICAL SAFETY MANAGEMENT
}

\section{DARIA PAKULSKA, SŁAWOMIR CZERCZAK, and EWA MICHALAK}

\author{
Nofer Institute of Occupational Medicine, Łódź, Poland \\ Department of Chemical Safety
}

\begin{abstract}
Objectives: The work is aimed to present and promote the Chemical Safety Management Training Hub for Chemicals Users (ChemSM-Hub) project implemented by the Nofer Institute of Occupational Medicine in cooperation with the Lodz University of Technology, Poland, and other partners from Germany (Oekopol GmbH), Greece (Prolipsis) and Romania (Romtens). The project is co-funded by the European Commission under the Erasmus+ program, whose aim is to support downstream users (DUs) and distributors (Ds) of chemicals in complying with the REACH and CLP Regulations by developing an innovative training program in chemical safety management (CSM), available via the online project platform, adapted to the real needs of the target groups. Material and Methods: The methodology for implementing the ChemSM-Hub project includes: 1) conducting survey research among the target groups, 2) conducting a state-of-the-art review of literature and websites, 3) developing the Dissemination and Promotion Plan, 4) developing the Monitoring and Evaluation Procedure, 5) developing the CSM training curriculum, 6) designing the project e-learning platform and mobile app, 7) developing the "Training pattern for trainers" guidance, and 8) organizing training events. Results: The project is being implemented in response to the changing EU legislation on chemicals. As a result of the project, a CSM training program has been established consisting of 3 modules (introductory, basic and advanced) with varying degrees of complexity. In addition, a pocket guide has been developed that contains basic information for DUs and Ds regarding the REACH and CLP Regulations, as well as the "Training pattern for trainers" guidance containing a CSM training session plan for trainers. All these materials will be available via the project platform, and their selected elements also via a mobile app. Conclusions: The publication is aimed to familiarize the potential users of the ChemSM-Hub training program with its thematic scope, the structure of the training and the expected results. It is also a way to promote online training adapted to the needs of its target groups. Int J Occup Med Environ Health. 2020;33(3):247-61
\end{abstract}

Key words:

chemical safety management, downstream users, distributors, Erasmus + program, training program, e-learning platform

\section{INTRODUCTION}

The chemical industry is one of the largest production sectors in the EU, but the "success" of the chemical industry can, unfortunately, become the Achilles' heel of modern times. The progressing chemization inevitably leads to the devastation of the natural environment and is the cause of many dangerous diseases. A review of the chemical policy conducted by the European Commission in 1998 showed that the legal regulations in force at that time did not provide sufficient protection against the harmful effects of produced and used chemicals. The existing system, being a mosaic of many directives and ordinances, distinguished between chemicals registered in September 1981 ("existing substances") and those introduced to the market since then ("new substances").

In 2007, Regulation (EC) No. 1907/2006 of the European Parliament and of the Council, commonly referred to as REACH, was introduced, which completely changed

Funding: this work was supported under the Erasmus+ Program of the European Union (project No. 2017-1-PL01-KA202-038432, entitled "Chemical Safety Management Training Hub for Chemicals Users - ChemSM-Hub," project manager: Daria Pakulska, Ph.D.).

Received: October 8, 2019. Accepted: December 18, 2019.

Corresponding author: Daria Pakulska, Nofer Institute of Occupational Medicine, Department of Chemical Safety, św. Teresy 8, 91-348 Łódź, Poland (e-mail: Daria.Pakulska@imp.lodz.pl). 
the paradigm in the approach to managing chemical safety. The scope of the REACH Regulation covers processes, such as registration, evaluation, authorization and restriction on chemicals. The most important and fundamental novelty was the transfer of the burden of responsibility for chemical safety from member states to companies. Under the REACH Regulation, small and medium-sized enterprises (SMEs) that cannot afford to hire a specialist in the field of chemical safety management (CSM) have the same tasks as large companies and cannot be exempted from any chemical safety obligations.

Two years after the implementation of the REACH Regulation, another complex regulation came into force, i.e., Regulation (EC) No. 1272/2008 of the European Parliament and of the Council, commonly referred to as CLP. The provisions of the REACH and CLP Regulations complement each other. The REACH Regulation defines the company's obligations depending on the role it plays in the supply chain, while the CLP Regulation sets forth its obligations related to the classification, labeling and packaging of chemicals. Under the new provisions, the obligations of all companies in the supply chain have been changed. Manufacturers and importers that place chemicals on the market must ensure the safety of all operators in the supply chain, adequately informing them on the risks and defining risk management measures. New responsibilities have been imposed on all actors in the supply chain, including downstream users (DUs) and distributors (Ds) of chemicals the numerically largest groups of companies in the supply chains that are present in every industry. Most of these DUs and Ds of chemicals belong to the SMEs sector, having limited resources for expensive and time-consuming training. What is more, the opportunities for non-commercial training in the field of CSM appear to be insufficient.

An assessment of the state of implementation of the REACH and CLP Regulations leads to the conclusion that the people responsible for chemical safety among DUs and Ds of chemicals are either insufficiently trained or lack the knowledge and understanding of the EU legislation in this field. There is a widespread belief that the new EU regulatory framework for chemicals is too complex; moreover, the applicable regulations change over time, causing additional problems for companies.

Companies declare problems with defining their legal obligations under the REACH and CLP Regulations, and they claim to have insufficient skills, e.g., in classifying chemical mixtures and assessing exposure in the work environment. A survey carried out by the European Chemical Agency (ECHA) in 2010 and 2013 [1,2] showed that many companies lacked the required safety data sheet (SDS). Some companies failed to meet the SDS requirements for the language, structure and content, and the obligation to pass them down the supply chain. In some companies, unregistered substances were used but the required information was not provided down the supply chain.

A preliminary survey and an assessment of the needs of the workplace regarding CSM training revealed a high demand in this area. In response to such needs, the team of the Department of Chemical Safety, the Nofer Institute of Occupational Medicine (NIOM) in Łódź, Poland, together with the Lodz University of Technology and partners from Germany (Oekopol GmbH), Romania (Romtens) and Greece (Prolepsis), has been implementing a 3-year (01/09/2017-31/08/2020) project entitled the Chemical Safety Management Training Hub for Chemicals Users (ChemSM-Hub), co-funded from European sources under the EU Erasmus+ program.

The project consortium is structured in such a way that the EU member states that make up the consortium present different levels of development of the chemicals market and different experiences in applying EU rules. Table 1 describes the organizations included in the project consortium.

The main objective of the project is to support companies in complying with the REACH and CLP Regulations by preparing a CSM training program available free of 
Table 1. The ChemSM-Hub project consortium

\begin{tabular}{lc}
\hline Country & Organization \\
\hline Poland & (\$) NOFER INSTITUTE OF OCCUPATIONAL MEDICINE
\end{tabular}

The Nofer Institute of Occupational Medicine (NIOM) in Łódź was founded in 1954. It is a scientific-research institution that deals, in general, with the issues of public and environmental health, with special emphasis on subjects associated with broadly understood occupational medicine. The elementary task of the Institute is to perform scientific research as well as to conduct implementation and expertise works in the field of occupational and environmental health hazards and risks. In the realization of its tasks, the Institute cooperates with universities, the Polish Academy of Sciences, research institutes and other scientific units, scientific and occupational associations, non-governmental organizations, and healthcare units in the country, as well as with equivalent organizations and institutions abroad. http://www.imp.lodz.pl/home_en/

Poland

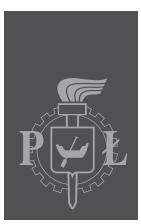

The Lodz University of Technology (TUL) came into existence in 1945 as a governmental, public body. More than 21000 students are currently studying at the University (including 800 Ph.D. students). The educational and scientific tasks of the University are carried out by about 3000 staff members. The Lodz University of Technology is a leader in research in numerous areas of science and technology, both in Poland and abroad. A large body of research concerns new IT applications in the areas of biotechnology, electronics, telecommunication, computer science, materials engineering, technologies and nanotechnologies, medicine, environmental protection, biomedical engineering, textile engineering, etc. The Lodz University of Technology cooperates with $>300$ institutions in 40 countries. It takes part in EU Framework Programs (15 projects in FP5, 30 in FP6, 23 in FP7) and in the Horizon 2020, Erasmus Mundus and Erasmus+ programs.

https://www.p.lodz.pl/en/

Germany

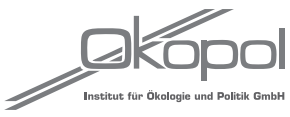

Oekopol - Institute for Environmental Strategies (Oekopol $\mathrm{GmbH}$ ) is a well-known environmentally-focused consulting group based in Germany, active at the European level for over 25 years. Oekopol $\mathrm{GmbH}$ experts operate in a broad variety of environmentally relevant areas including chemicals legislation, waste management and waste legislation, the prevention and control of industrial installations, and policies on environmentally sound products, in order to assist with the conservation of resources and to limit the use of hazardous substances.

https://www.oekopol.de/en/

Greece

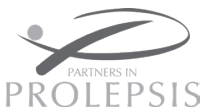

The Institute of Preventive Medicine, Environmental and Occupational Health (Prolepsis), a civil non-profit organization, was established in 1990 in Athens. With a strong belief in health being a fundamental right, Prolepsis has undertaken a leading role in the field of public health, by designing and implementing initiatives on various health issues and in different sectors (e.g., education, workplace), targeting a wide range of audiences, such as children and adolescents, women, migrants, and the elderly, and different types of occupational groups, such as health professionals, as well as policy makers, other NGOs and decision-makers. As a coordinator or partner, Prolepsis has participated in approximately $50 \mathrm{EU}$ co-funded and numerous national projects implementing research, applied and educational initiatives, aiming at health promotion and education of the public, policy change, and tackling health inequalities. http://www.prolepsis.gr/en/ 
Table 1. The ChemSM-Hub project consortium - cont.

\begin{tabular}{l}
\hline Country \\
\hline Romania \\
The Romtens Foundation is a non-governmental organization with $>20$ years' experience in the field of workplace \\
health promotion. It is the first Romanian organization to organize such activities on the national level, and the only \\
Romanian organization member of the European Network for Workplace Health Promotion. At the same time, \\
in the last 10 years, the Foundation has gathered expertise - nationally and at the European level - regarding \\
programs and projects evaluation and monitoring, having evaluated $>60$ training courses (the Kirkpatrick model) \\
and $>100$ informational and educational campaigns, 10 websites, as well as research programs, public policies and \\
organizations. In the last 18 years, Romtens has organized accredited training courses for physicians, managers and \\
employees, with $>4000$ participants. \\
http://romtens.ro/en/
\end{tabular}

charge via the e-learning platform (ChemSM-Hub) and a mobile app.

It is assumed that the project will contribute to the promotion of online training methods that are not institutionalized but depend on the individual needs and time of the people concerned. The creation of such a modern training hub for employees working with chemicals will increase their qualifications and market competitiveness. It is assumed that the ChemSM-Hub platform will facilitate studying the subject at any time and in any place, using a laptop, a tablet or a smartphone, and will be a great alternative to classic classroom-based training.

\section{Aims of the project}

The strategic aims of the project are to strengthen the target groups' competences in the field of CSM, to increase the awareness of relevant professional communities on the new European legislation on CSM (the REACH and CLP Regulations), and to enhance trainers' skills in creating and conducting CSM training in partner countries. The authors intend to achieve the above aims by providing free-of-charge access to an innovative and comprehensive training program, available via the e-learning platform (ChemSM-Hub) that was designed for both self-education and group training. The project is expected to in- crease the knowledge of the DUs obligations arising from the REACH and CLP Regulations, including the adaptation of safety data sheets for chemical mixtures to new legal requirements, the main procedures of the REACH and CLP Regulations, as well as the knowledge about various sources of support for DUs, including the ECHA support.

\section{MATERIAL AND METHODS}

The project implementation process was divided into the following steps:

- setting training goals,

- defining the target group of the project,

- developing the Dissemination and Promotion Plan,

- developing the Monitoring and Evaluation Procedure,

- conducting a study on the availability of CSM training in the EU, and the needs of the project target groups as regards CSM training (output 1 ),

- developing the e-learning hub with a mobile app for training and know-how exchange (output 2),

- developing a comprehensive training curriculum,

- developing introductory and basic modules as well as a pocket guide for DUs and Ds of chemicals (output 3),

- developing an advanced module (output 4),

- developing the "Training pattern for trainers" guidance (output 5), 
- organizing 2 events crucial for the evaluation of the entire training materials and the functionality of the training platform (short-term joint staff training and shortterm training for learners),

- providing public access to the entire training program via the project platform and a mobile app.

\section{Project target groups}

Based on the state-of-the-art analysis, it has been established that large chemical companies are usually very well prepared to fulfill the obligations under the REACH and CLP Regulations, while among DUs and Ds of chemicals there are many SMEs with much less awareness of chemical hazards, not having funds for training, and often operating without any external support. The above-mentioned findings have become the basis for selecting the project target groups, i.e., employers and employees responsible for CSM among DUs of chemicals, including professional and industrial chemical users, formulators, fillers, article producers, craftsmen, service providers, distributors of chemicals, as well as occupational safety and health $(\mathrm{OSH})$ specialists and state authorities, like sanitary inspection and labor inspection.

\section{Analysis of the availability of CSM training}

The first step in the implementation of the ChemSM-Hub project was the state-of-the-art analysis of the availability of CSM training based on a review of literature and online materials. The study was carried out in all partner countries (Poland, Germany, Greece and Romania). To ensure the quality of this work and to unify the way of conducting the research, a guide on "How to perform the literature and Internet materials review" was developed. The guide includes the aim of the study, along with tips on how to perform the literature review and the selection of appropriate literature. Additionally, the template for reporting the results was provided to ensure the uniformity of collecting data. The template includes the following: the name of the country where the training was conducted, the name and short description of the training, a link to the specific training website, the type of materials available (e.g., training sheets, guidance), the duration and kind of training performed (e.g., a seminar, a workshop, a report), and the target groups and industry covered by the study.

\section{Questionnaire-based assessment of training needs}

The project team was interested in both the individual training needs of the target groups from their point of view, and the areas requiring an improvement of professional skills from the perspective of the management staff.

In order to obtain the most reliable and comprehensive opinion, the research was carried out according to the developed survey guide containing setting goals, expected results, target group definitions, techniques for data collection, research tools (e-mail, phone, post and direct interview based on a survey guide), and a specific timeline. A preliminary understanding of the relevant training opportunities and gaps specified in the literature and website review served as a basis for the questionnaire design. The online survey was conducted using the cloud-based software provided by SurveyMonkey, a service company, that also served for statistical analysis. The study covered 253 respondents from all partner countries, including OSH specialists, employers and employees responsible for chemical safety among DUs and Ds of chemicals, and other stakeholders, like specialists from supervisory bodies and universities. The questionnaire covered the following topics: the gender, age, occupation and affiliation of the participants, their recent CSM training, their expectations regarding the thematic scope and form of CSM training, their need to introduce a practical part to training, and other.

\section{Development of the Dissemination and Promotion Plan}

As part of the project, several procedures were implemented to promote and disseminate the project results, 
Table 2. Dissemination and promotion activities carried out during the ChemSM-Hub project life cycle

\begin{tabular}{|c|c|}
\hline Dissemination activity & Purpose \\
\hline Project logo and graphic identity & recognition and branding of the project \\
\hline Dissemination lists & broad dissemination of the project results \\
\hline Promotional campaign on the partners' websites & to raise awareness/inform \\
\hline $\begin{array}{l}\text { Publication of selected exercises included in training materials on Facebook } \\
\text { (ChemSM-Hub) }\end{array}$ & to raise awareness/engage \\
\hline Twelve e-newsletters (4 per year) in each partner language & to raise awareness/inform \\
\hline Leaflet (150 copies in each partner language) & to raise awareness/inform \\
\hline $\begin{array}{l}\text { Promotional campaign on social media (ChemSM-Hub dedicated pages } \\
\text { on Facebook and Twitter) }\end{array}$ & to raise awareness/inform \\
\hline Press release in each partner language prior to the National Info Days & to raise awareness/inform/engage/promote \\
\hline National Info Days in each partner country & to raise awareness/inform/engage/promote \\
\hline $\begin{array}{l}\text { Publication of a pocket guide for distributors and downstream users of chemicals } \\
\text { (100 hard copies in each partner language) }\end{array}$ & to raise awareness/inform \\
\hline E-learning platform ChemSM-Hub & to raise awareness/inform/engage/promote \\
\hline Mobile application & to raise awareness/inform/engage/promote \\
\hline Publications in specialist journals (at least 2) & to raise awareness/inform/promote \\
\hline
\end{tabular}

as well as to ensure their durability based on the Dissemination and Promotion Plan developed by the task leader. The main activities covered by the Plan are presented in the Table 2.

\section{National Info Days}

The event referred to as the National Info Days is one of the project promotion methods organized in each partner country. The purpose of the event is to provide the participants with information about the ChemSM-Hub project and to create an opportunity to increase cooperation between institutions providing training opportunities, companies, industrial hygienists associations, research institutions and other bodies.

\section{Newsletters}

ChemSM-Hub newsletters are short messages about specific aspects of the project, developed graphically using the MailChimp program and sent to interested parties, including the participants of the questionnaire survey conducted by the project team at the beginning of 2018. In addition, the newsletter aims to maintain a constant contact with target groups, and inform them about the project progress.

It is expected that, as a result of such promotional and dissemination activities, the project will benefit at least 300 people from the target groups. In addition, it is assumed that training providers/vocational education and training institutions in the field of CSM will contribute to the further dissemination of project results. The consortium agreed to maintain and regularly update training materials over the next 2 years after the completion of the project.

\section{Development of the Monitoring and Evaluation Procedure}

In order to improve the efficiency and effectiveness of the project while it is still in progress, and to improve its impact on the target groups, the ChemSM-Hub team, 
together with the task leader, developed the Monitoring and Evaluation Procedure. It includes the following instruments:

- process evaluation (project monitoring and assessing the satisfaction of the project stakeholders),

- outcome evaluation (a qualitative assessment of the main intellectual outputs),

- impact evaluation (an evaluation of training and dissemination activities).

In the middle of the project implementation period, the half-time evaluation of the project partners' satisfaction, based on a questionnaire conducted among the project team members, was carried out as agreed in the Monitoring and Evaluation Procedure.

The evaluation will cover intellectual outputs including:

- the training package,

- project meetings,

- the National Info Days (the Participants' Satisfaction Questionnaire),

- teaching and training activities,

- information and dissemination activities.

The entire training materials, including introductory, basic and advanced modules, as well as the pocket guide, will undergo evaluation in terms of their transferability, appropriateness, adaptability, comprehensiveness and other strategic features. The evaluation of the training materials and training platform functionalities is a multistage process based primarily on peer review within the project team itself, and then during two 5-day events considered as milestones of the project implementation. First of them (short-term joint staff training event - C1) will involve materials assessment by specialists and experts from each partner country, and the second one (short-term activities for learners - C2) - the evaluation of the training materials by the participants of pilot training $(\mathrm{C} 2)$. The participants of the $\mathrm{C} 2$ event will score the materials according to the dimensions within the $M a$ trix-Type Questionnaire.
In order to evaluate $\mathrm{C} 2$ (pilot training), the 4-level Kirkpatrick model [3] will be used. Due to some project restrictions, only 3 of them will be used: the first level (Reaction or Satisfaction) - the satisfaction survey, the second level (Learning) - the knowledge test, and the third level (Behavior) - an assessment of changing the participants' approach to the subject. In order to conduct a comparative analysis, 2 surveys will be conducted among the participants of the pilot training, i.e., the Pre-Evaluation Questionnaires and the Post-Evaluation Questionnaires. The evaluation of dissemination activities will be carried out via the project website using Google analytics.

\section{Development of a comprehensive training curriculum in CSM}

Based on the analysis of training needs as well as the exchange of professional knowledge between the partners, a comprehensive training curriculum in CSM has been developed. The training methodology reflects the top-down approach. In this context, the entire training package has been divided into 3 modules: introductory, basic and advanced. The modules are divided into training sessions. The introductory module contains 1 training session, the basic module 4 and the advanced module 8 training sessions. The introductory module is intended for self-education and serves as introduction to the basic terms and definitions used in the REACH and CLP Regulations.

The curriculum includes:

- the aims and objectives of the training session,

- the key ideas of the training session,

- the total number of 1-h lectures, the total number of exercises,

- the type of materials used with examples,

- the names of the authors of lectures and exercises,

- the names of experts responsible for the training materials.

The training sessions forming part of the basic and advanced modules include exercises. The duration of each 
training sessions and the number of proposed exercises depend on the complexity of the subject. For each training session, examples, exercises, a glossary and a list of source materials are provided. Each module ends with an exam based on randomly selected questions from all the exercises contained in the basic or advanced module. For the trainees who pass the exams, the system will automatically generate a certificate of completion of basic and/or advanced training.

\section{Designing the project website (an e-learning platform) and an app for mobile devices}

To ensure access to the widest possible audience, training materials will be available free of charge via the ChemSMHub e-learning platform and a mobile app. The only condition for using the platform is having a computer/laptop with internet access. Users of the ChemSM-Hub platform will be required to register first. The platform will create an environment in which the participants will be able to intuitively navigate through all sections, and after each training session check their knowledge using the included exercises. After successfully completing the exams, the trainees will be able to generate and print a certificate confirming the acquired skills.

\section{Development of the "Training pattern for trainers" guidance}

The "Training pattern for trainers" guidance is a road map of the entire training process covered by the ChemSMHub project. It will contain a description of each training session, learning objectives, teaching methods, session content and resources required, as well as exercises, case studies and frequently asked questions. The developed template will help to organize materials consistently over sessions. The guidance will be available for free to all stakeholders in Europe and will provide support to those who wish to organize training in the field of CSM in their workplace. It is assumed that the "Training pattern for train- ers" guidance will stimulate and promote high standards in vocational training based on the CSM training program delivered. The final version in English will be translated into national languages of the project partners and made available via the ChemSM-Hub e-learning platform.

\section{Organization of training events}

Two 5-day events are the milestones of the project implementation. The first one is named "short-term joint staff training events" $(\mathrm{C} 1)$ and the second "short-term activities for learners" (C2). These 2 events create a chance to improve the quality of training materials.

\section{Short-term joint staff training events $(C 1)$}

Short-term joint staff training (C1) took place in September 2019 in Romania, and aimed to assess and verify training materials by $\mathrm{OSH}$ experts and the project team. This event was absolutely crucial for the project results. All the materials already developed and circulated amongst the partners were peer-reviewed based on the feedback provided by experts.

\section{Short-term activities for learners (C2)}

The short-term activities for learners will take place in Poland. This is the second crucial event for assessing and improving the quality of training materials and the functionality of ChemSM-Hub. This time, the training materials will be evaluated by the target group during pilot training. The training itself will be interactive based on the cooperation of the trainer with the participants, using online tools available via ChemSM-Hub.

\section{RESULTS}

The analysis of training opportunities in EU countries, along with reviewing the existing body of knowledge and exploring the needs of target groups, helped to obtain a reliable picture of training gaps related to CSM among DUs and Ds of chemicals. 


\section{Analysis of educational opportunities in the field of of CSM in partner countries and training needs among target groups}

A literature and website review as well as a survey among the project target groups were conducted in the spring of 2018 in each partner country. The participants of the survey were selected mostly from SMEs, supervisory bodies and universities. The survey was conducted in national languages and involved 253 respondents from all partner countries, including representatives of companies, supervisory bodies, universities and other organizations. The organizations participating in the survey are presented in Table 3.

Micro, small, medium-sized and large enterprises participated in the survey. Most respondents (36\%) worked in chemicals-related sectors (dyes, paints, detergents, toilet preparations and man-made fibers). Among the respondents, the largest group were women aged $30-50$ years with a university degree.

A review of the literature and websites showed that, at the EU level, the available training was generally conducted in English. Most training sessions were free-of-charge webinars available via the ECHA websites with a duration of 1-2 h. At the member state level, training was usually offered by commercial providers and conducted in national languages by specialized educational services. In Poland and Greece, relevant training was also offered by universities. Training sessions were mostly face-to-face and lasted for a 1 day. Online training in CSM was identified in Greece and Poland, but not in Germany or Romania. In Romania, only 7 face-to-face training sessions were identified in the last 2 years.

As for the preferences regarding the form of training, about $11 \%$ of the respondents chose online training as their preferred training mode. The respondents pointed to the usefulness of this type of training due to unlimited access at any time and in any place. Concerning the duration, 1-5-day or 1-2-day training seemed to be the most
Table 3. Respondents $(\mathrm{N}=253)$ by organization taking part in the Questionnaire to Specify Educational Opportunities and Needs in Chemical Safety Management of Downstream Users and Distributors of Chemicals, conducted in spring 2018 in Poland, Germany, Greece and Romania

\begin{tabular}{lc}
\hline \multicolumn{1}{c}{ Interviewee organization } & $\%$ \\
\hline Company & 54.3 \\
Supervisory body (e.g., Sanitary Inspection) & 26.3 \\
University & 10.7 \\
Other (e.g., Environmental Services) & 12.6 \\
\hline
\end{tabular}

popular. The reasons for training given in the survey were changes in legislation, employer orders or self-interest. The majority of the respondents were interested in training at the basic and intermediate level. Particular interest concerned the following issues:

- the REACH and CLP Regulations,

- obligations of companies under REACH and CLP,

- the classification and labeling of substances and mixtures according to CLP,

- the reading and understanding of safety data sheets,

- the development of safety data sheets,

- the classification of chemical mixtures,

- information on the transport of hazardous chemicals in the safety data sheet,

- the reading and understanding of exposure scenarios,

- the development of exposure scenarios,

- restrictions under REACH,

- risk assessment, control of chemical hazards/prevention measures,

- emergency procedures,

- obligations of storekeepers under REACH,

- information on the appropriate disposal of chemicals in the safety data sheet.

Most respondents pointed to the need to equip training materials with practical exercises to facilitate the learning process. The participants declared their willingness to take part in practical exercises in all 5 proposed thematic areas: 
- the classification of mixtures,

- the labeling of mixtures

- the development of safety data sheets,

- the development of exposure scenarios,

- risk assessment.

The survey showed that only $13 \%$ of the last training sessions attended by the respondents included a practical part.

\section{E-learning hub with a mobile app for training} and know-how exchange - expected results

The ChemSM-Hub e-learning platform creates a virtual learning environment which not only enables users to pursue self-training and use the adequate assessment tools to communicate with other learners and trainers, but also serves as a central point for the exchange of information and ideas on CSM. The hub and mobile app will create a possibility to reach the largest possible audience irrespective of the time, work or place of residence. Access to the trial version of the platform is possible via https:// chemsm-hub.eu/training/, user name: ChemHUB, password: HUB99.

Particular attention was paid to ensure an intuitive navigation that will allow people with basic ICT skills to use the resources of the platform. Users through e-platform will have access not only to training sessions equipped with exercises, but also to the "Training pattern for trainers" guidance, showing how to implement the acquired knowledge in their own businesses.

The e-learning hub will be created using the Open Source Learning Management System (LMS). In this virtual learning environment, there will be room for training modules and assessment tools. An additional element of the platform will be communication and networking tools that will allow members to register their profiles and to identify other participants to create thematic community groups. This will also facilitate dialogue, brainstorming and discussion also with teachers.
In addition to the ChemSM-Hub platform, a mobile app for Android devices will be created whereby users will find basic terms, definitions and procedures related to the REACH and CLP Regulations.

It is intended that the ChemSM-Hub platform will be maintained beyond the project for at least 2 years, and its content will be available for free in English, Polish, German, Greek and Romanian. Beyond the project, other languages can be added for further distribution of training materials to other countries.

\section{CSM training curriculum - the introductory,}

\section{basic and advanced level}

Considering the extensive thematic scope, materials were divided into 3 modules: introductory, basic and advanced. The introductory module was designed to facilitate the understanding of the issues contained in the basic and advanced modules, and is an introduction to the basic concepts of both the REACH and CLP Regulations. Each training module is divided into working sessions. The introductory module contains 1 training session, the basic module 4 and the advanced module 9 working sessions. The modules were designed for both self-education and group training in the workplace, independently or additionally.

The contents of the introductory, basic and advanced modules are presented in Table 4.

All training materials are first developed in English and then translated into Polish, Greek, German and Romanian (the languages of the project partners) in order to extend their accessibility to the target groups from partner countries. Peer review among the partners will be made before launching the materials onto the e-learning platform.

The evaluation of the training materials was conducted during the short-term joint staff (C1) in Romania and the final evaluation will be conducted during the shortterm activities for learners (C2) planned for June 2020 in Poland. 
Table 4. The modules and content of the ChemSM-Hub training program

\begin{tabular}{cll}
\hline & \multicolumn{2}{c}{ Training sessions } \\
\hline introductory module & \multicolumn{1}{c}{ basic module } & \multicolumn{1}{c}{ advanced module } \\
\hline - Basic concepts & - Introduction to REACH & - Safety data sheets - technical details and practical tips \\
of REACH and CLP & - Introduction to CLP & for formulators \\
& - Introduction to safety data sheets & - Restrictions procedure under REACH \\
& - Introduction to ECHA and other & - Authorization procedure under REACH \\
& sources of information & - Classification of mixtures - physical hazards \\
& & - Classification of mixtures - health hazards \\
& - Classification of mixtures - environmental hazards \\
& - General rules of labeling \\
\hline
\end{tabular}

CLP - Regulation of the European Parliament and of the Council (EC) No. 1272/2008; ECHA - European Chemicals Agency;

REACH - Regulation of the European Parliament and of the Council (EC) No. 1907/2006.

After the completion of the project, other languages can be added when the e-learning platform and training materials get further distributed to other countries. The project team expects that, after completing the training program, the participants will obtain the competences in the areas presented in Table 5.

\section{Pocket guide}

In addition to the training modules, a pocket guide for DUs and Ds of chemicals was developed. The guide refers to the REACH and CLP Regulations, and covers the most important issues in the field of CSM. It contains useful information for the target groups, including basic concepts and terms used in the REACH and CLP Regulations, the main procedures of $\mathrm{REACH}$, the identification of the companies' role in the supply chain, legal obligations of DUs and Ds in the light of the REACH and CLP Regulations, the communication flow in the supply chain, the safety data sheet (SDS) and the extended SDS, the main procedures of CLP, the classification of chemical substances and mixtures, the labeling of chemical substances and mixtures, the structures of the REACH and CLP Regulations, lists of hazard statements (H phrases), EU hazard statements (EUH phrases), EU precautionary statements (P phrases), signal words, pictograms, and label samples.
The pocket guide will be available in both paper and electronic versions via the ChemSM-Hub platform, in English and in the languages of the project partners.

\section{The "Training pattern for trainers" guidance - expected results}

The "Training pattern for trainers" guidance will be published on the e-learning platform and will be available to all interested parties, including OSH specialists, for their training activities. The guidance will be developed in English and then translated into the national languages of the project partners. It is expected that, after placing the guidance on the platform, which is scheduled for the end of March 2020 for the English version and for the end of June 2020 for the version in the languages of the partners, the number of downloads will be at least 100 in each of the languages available.

\section{Newsletters}

As part of the project promotion and dissemination activities, the following newsletters on ChemSM-Hub have been developed:

- Newsletter No. 1 contains an introduction to the issues covered by the project. It briefly explains the purpose of the project, defines the target groups and the training 
Table 5. The level and scope of qualifications obtained after completing the ChemSM-Hub program

\begin{tabular}{|c|c|c|}
\hline \multicolumn{3}{|c|}{ Level of competence after the training } \\
\hline introductory module & basic module & advanced module \\
\hline $\begin{array}{l}\text { - Become familiar with the basic concepts } \\
\text { and definitions of REACH and CLP } \\
\text { - Become familiar with the chemicals and } \\
\text { activities covered by REACH and CLP } \\
\text { - Know the main players under REACH } \\
\text { - Become familiar with the roles of com- } \\
\text { panies and their obligations in the supply } \\
\text { chain under REACH } \\
\text { - Become familiar with the safe use proce- } \\
\text { dures under REACH } \\
\text { - Become familiar with the main proce- } \\
\text { dures of REACH and CLP } \\
\text { - Become familiar with interface between } \\
\text { REACH and CLP }\end{array}$ & $\begin{array}{l}\text { - Get acquainted with REACH } \\
\text { and CLP } \\
\text { - Become familiar with the legal grounds } \\
\text { for compiling and delivering safety data } \\
\text { sheets } \\
\text { - Understand the role of safety data } \\
\text { sheets in the supply chain } \\
\text { - Get acquainted with criteria for mix- } \\
\text { tures classification - general rules } \\
\text { under CLP } \\
\text { - Become familiar with ECHA websites } \\
\text { - Understand ECHA responsibilities } \\
\text { - Be able to find necessary information } \\
\text { on ECHA websites } \\
\text { - Be able to find legal acts on EUR-Lex } \\
\text { websites }\end{array}$ & $\begin{array}{l}\text { - Know how to develop safety data sheets } \\
\text { and exposure scenarios } \\
\text { - Be able to classify mixtures according to } \\
\text { the given criteria of physical, health and } \\
\text { environmental hazards under CLP } \\
\text { - Know how to find the concentration } \\
\text { limit (specific or generic) } \\
\text { - Be able to calculate acute and chronic } \\
\text { aquatic toxicity, using the mathematical } \\
\text { formulas given } \\
\text { - Become familiar with legal bases of } \\
\text { restrictions under REACH } \\
\text { - Become familiar with the legal grounds } \\
\text { concerning substances of very high } \\
\text { concern (SVHC) and the authorization } \\
\text { procedure under REACH } \\
\text { - Get acquainted with the classification } \\
\text { and labeling list (C\&L Inventory) } \\
\text { - Get to know the general rules for } \\
\text { the labeling and packaging of chemicals } \\
\text { under CLP }\end{array}$ \\
\hline
\end{tabular}

C\&L Inventory - Classification and Labelling Inventory; CLP - Regulation of the European Parliament and of the Council (EC) No. 1272/2008; ECHA - European Chemicals Agency; EUR-Lex - access to the EU law; REACH - Regulation of the European Parliament and of the Council (EC) No. 1907/2006.

activities to be undertaken, including surveys among the target groups and the assumed project results.

- Newsletter No. 2 is dedicated to the basic module. It contains a thematic scope of the lectures and exercises envisaged under this module, and announces the creation of a pocket guide as its complementary part. In addition, it lists the skills that the participant should get after completing the course at the basic level.

- Newsletter No. 3 summarizes the results of a survey conducted among the target groups in all project partner countries, regarding the opportunities and training needs. It draws attention to these issues in CSM which have not been included in the training the participants have already received, and points out the need to include practical exercises in all proposed subjects.

- Newsletter No. 4 concerns the procedure for project monitoring and evaluation. It encourages the addressees to take part in the National Info Days, as well as to familiarize themselves with the proposed training program and the "Training pattern for trainers" guidance. It also announces pilot training in Romania and Poland, whose aim is to assess the training materials and functionality of the e-learning platform and the mobile app.

- Newsletter No. 5 concerns the emerging online platform and the app for mobile devices, designed and created by the Lodz University of Technology.

Subsequent newsletters will be issued every 2-3 months. 


\section{Short-term activities for learners - expected results}

The pilot training referred to as $\mathrm{C} 2$ - short term training for learners, will be held in June 2020 in Poland in attendance of the target groups. This event will be the last stage of evaluation of the training materials. It will take the form of blended interactive training, where traditional training will be enhanced with online tools available via ChemSM-Hub.

\section{DISCUSSION}

The purpose of CSM is to ensure the use of chemicals in such a way as to eliminate or limit their hazardous effects on people and the environment. The introduction of the REACH and CLP Regulations have changed the paradigm of CSM in workplaces. Within the EU, CMS remains a top priority for European chemical companies. The problem is that these Regulations are very extensive and thematically complex, which causes that their provisions are not fully understood by companies. The most common reasons for insufficient training are financial barriers, a lack of time, staff shortages, a lack of substitution for trainees, and a lack of motivation. In addition, the management staff is often against the allocation of funds for this purpose.

Unfortunately, most training in CSM is paid, which creates a financial barrier for most companies, especially small and medium-sized ones. The ECHA studies, REACH-ENFORCE 1 (REF-1) and REACH-EN-FORCE 2 (REF-2), regarding the degree of fulfillment of the obligations imposed by the REACH Regulation, the first of which concerned pre-registration, registration and safety data sheets, and the second the obligations of downstream users and formulators of mixtures, have shown that companies have difficulties to cope with these responsibilities.

A state-of-the-art analysis of the present situation in vocational training in CSM and the conducted surveys have shown that companies do not have a sufficient knowledge and understanding of the REACH and CLP Regulations.
This has motivated the team of the Nofer Institute of Occupational Medicine in Łódź, Poland to design a training program that would support downstream users and distributors of chemicals in complying with the provisions of the REACH and CLP Regulations. Thanks to the use of e-tools in the proposed training program, the project has the chance to reach the widest possible audience, including people excluded from the labor market and people who are temporarily unable to work, but who are interested in improving their professional qualifications in the field of CSM. In addition, the project can play an important role in promoting new teaching methods that are not institutionalized but depend on the individual needs of people.

As revealed by the conducted surveys, face-to-face training sessions organized outside the company by specialized trainers are the most desirable. Online training only received support from $10.8 \%$ of the respondents, which is likely due to the still insufficient popularity of online training and the inability to use online tools by most respondents. Probably not without impact on the outcome of the survey was the age of the respondents $(19.35 \%<30$ years old; $52.42 \%<50$ years old; $28.23 \%>50$ years old), suggesting preferences for traditional training methods.

The availability of the training program via the e-learning platform enables both self-education and group training. The "Training pattern for trainers" guidance will support trainers in conducting CSM training, while OSH specialists, who supervise or train other employees, will gain an open and effective training tool that will allow systematic and continuous vocational training, both for themselves and for other employees in their work environment. Vocational education and training (VET) providers will benefit primarily from the methodology of effective training in the field concerned by the project. It is anticipated that the project will be able to influence decision-makers to support training in this field. In addition, the active participation of the target groups in the development of training materials and tools allows taking into account their 
perspective and adapting the training program to their needs

The state-of-the-art analysis indicates that educational support should be addressed directly to employees, but not through the workplace, and this condition is met by e-training. The proposed project is a good example of transforming the boring teaching process into the pleasant activity. Everyone using the training program should take responsibility for the teaching process in their own hands by selecting the appropriate training sessions and determining their own learning pace, according to their predispositions. The offered training program can be particularly useful for those who use and develop material safety data sheets (MSDS), who are responsible for packaging and classifying chemicals, who carry out chemical safety assessments, or who are involved in managing any of these activities.

Partner institutions are also among the beneficiaries of the project. These beneficiaries will gain experience and know-how in the field of CSM - a relatively new area in vocational education and training for both trainees and trainers. At the same time, the partners will have the opportunity to strengthen their existing networks for further cooperation, as well as to expand and increase contacts with relevant stakeholders and institutions involved in the project.

The authors of this study assume that the training program they are offering will make its users "best in class" in terms of the knowledge of the REACH and CLP Regulations, and increase their ability to implement these Regulations in their daily professional practice. ChemSM-Hub is intended both for self-education and for trainers in their professional work. It will enable conducting blended interactive training, in which traditional classroom-based training will be combined with new electronic technologies. Future users will be more independent in their learning process. In the long run, the project may also help to level off the transnational differences in CSM standards and to fulfill the requirements of the chemicals market based on free movement of goods.

The e-learning platform, with all its training materials, will be available for free to all stakeholders in Europe and beyond, thus stimulating and promoting high standards in vocational training and allowing to conduct further training based on the guidance for trainers.

The project will contribute to the familiarization with the EU standards, which may result in increased safety in companies and better qualified workers in Europe. The long-term effect of the project will be an increased protection of customers' health by offering properly labeled and safer chemical products.

\section{CONCLUSIONS}

The ChemSM-Hub project is implemented in response to the needs and expectations of the project target groups requiring support in fulfilling their obligations arising from the REACH and CLP Regulations.

The project target groups are downstream users and distributors (of chemicals, mostly belonging to the SME sector, requiring special support due to insufficient funds for training.

The ChemSM-Hub training program is a great alternative to commercial training. It will be available free of charge via the ChemSM-Hub platform and the mobile app.

The project is intended both for self education and for trainers conducting classic training as well as blended training combining classroom-based training with online tools. The "Training pattern for trainers" guidance was developed as a road map for trainers.

The ChemSM-Hub training program consists of 3 modules, differing in the thematic scope and degrees of complexity. The introductory module will serve mainly for self-education and a general familiarization with the REACH and CLP Regulations. The other 2 modules (basic and advanced) will be supplemented by practical exercises. The pocket guide for downstream users and 
distributors of chemicals will support the target groups in daily practice.

The authors expect that the ChemSM-Hub project will contribute to the popularization of e-training which facilitates studying at any time and in any place, and, as a result, improve the qualification and competitiveness of the trainees on the labor market.

\section{ACKNOWLEDGMENTS}

The authors would like to express their appreciation and thanks to all those who devoted their time and knowledge to the implementation of this project. First, they are grateful to Małgorzata Kupczewska-Dobecka, M.Sc. Eng., Renata Soćko, Ph.D., Ewelina Czubacka, Ph.D. Eng., and Katarzyna Konieczko, M.Sc. Eng. (NIOM, Poland) for preparing earlier versions of the training materials. This really helped the authors to finalize the training materials. A special gratitude goes to Olaf Wirth, Ph.D. (Oekopol GmbH, Germany), and Theodor Haratau, M.D., MBA, (Romtens, Romania), who shared their experience and provided specialist knowledge. A very special gratitude goes to Piotr Jan Gromiec, Ph.D. Eng. (Poland), Isabela Banduch, Ph.D. Eng. (Oekopol GmbH, Germany), Monika Toaje, M.Sc., and Catalin Cervicescu, M.Sc. Eng. (Romanian Labour Inspection, Romania), and also to Anastasia Pantazopoulou M.D., Ph.D. (Prolepsis, Greece), for their verification of the training materials and contribution to the preparation of the final versions. A special mention is made of the colleagues from the Lodz University of Technology, Piotr Jóźwiak,
Ph.D. Eng., for preparing the project website, and Grzegorz Szymański, Prof. Ph.D. Eng., for creating the project e-learning platform. Finally, the authors' special thanks go to members of the Greek team, Pania Karnaki, M.Sc., Matina Kouvari, M.Sc., and Ioannis Koutelidas, M.A. (Prolepsis, Greece), for the promotion and dissemination activities, and to members of the Romanian team, Simona Stefanescu, M.Sc., Theodor Haratau, M.D., MBA (Romtens, Romania), for the monitoring and evaluation of the project outcomes.

\section{REFERENCES}

1. European Chemicals Agency, Forum for Exchange of Information on Enforcement. Results of the forum coordinated REACH enforcement project on registration, pre-registration and safety data sheets. Project report of the REACHEN-FORCE-1 project [Internet]. Helsinki: European Chemicals Agency; 2010 [cited 2019 Oct 1]. Available from: https://echa.europa.eu/documents/10162/13585/ref-1_project_report_conclusions_en.pdf.

2. European Chemicals Agency, Forum for Exchange of Information on Enforcement. Obligation of downstream users formulators of mixtures. Forum REACH-EN-FORCE-2 project report [Internet]. Helsinki: European Chemicals Agency; 2013 [cited 2019 Oct 1]. Available from: https:// echa.europa.eu/documents/10162/13577/forum_report_ ref2_en.pdf.

3. Kirkpatrick DL, Kirkpatrick JD. Evaluation of programs: the four levels. 3rd ed. Berrett-Koehler Publishers; 2006.

This work is available in Open Access model and licensed under a Creative Commons Attribution-NonCommercial 3.0 Poland License - http://creativecommons.org/ licenses/by-nc/3.0/pl/deed.en. 